\title{
A new approach for satisfactory pensions with no guarantees
}

\section{Carmen Boado-Penas ${ }^{1} \cdot$ Julia Eisenberg ${ }^{2} \cdot$ Axel Helmert $^{3} \cdot$ Paul Krühner $^{1}$}

Received: 25 March 2019 / Revised: 9 December 2019 / Accepted: 11 December 2019 /

Published online: 31 December 2019

(c) The Author(s) 2019

\begin{abstract}
The increase in longevity, the ultra-low interest rates and the guarantees associated to pension benefits have put significant strain on the pension industry. Consequently, insurers need to be in a financially sound position while offering satisfactory benefits to participants. In this paper, we propose a pension design that goes beyond the idea of annuity pools and unit-linked insurance products. The purpose is to replace traditional guarantees with low volatility, mainly achieved by collective smoothing algorithms and an adequate asset management. With the aim of offering security to the insured, we discuss the optimisation of some key variables of the proposed pension product to target both a satisfactory level of the initial pension and stable pension payments over time. By combining such well-known products as unit-linked and annuities, we show that it is possible to design a pension product with both high-expected return and low risk for the policyholder. However, differently than in the classical unit-linked framework, we do not allow the individuals to choose the underlying funds. Instead, the funds are under the surveillance of an insurance company's professional risk management, which induces better informed decisions.
\end{abstract}

Keywords Pensions · Guarantees · Unit-linked contracts · Ultra-low interest rates · Collective mechanism $\cdot$ Volatility smoothing

JEL Classification $\mathrm{G} 18 \cdot \mathrm{G} 22 \cdot \mathrm{J} 32$

Julia Eisenberg

jeisenbe@fam.tuwien.ac.at

1 University of Liverpool, Liverpool, UK

2 TU Wien, Vienna, Austria

3 msg life, Vienna, Austria 


\section{Introduction}

On the 16 March 2016 the European Central Bank (ECB) cut the fixed rate to zero and the recent policies of the ECB suggests that this situation will last for the next years and probably even decades. According to the European Insurance and Occupational Pensions Authority (EIOPA), more than half of European life insurance companies are guaranteeing a return to policyholders higher than the local 10-year government bond. In particular, since 2015, Switzerland has a negative long-term interest rates (between -0.5 and $0 \%$ ) while the range of values in Germany, the Netherlands and Belgium goes from 0 to $1 \%$.

Protracted ultra-low interest rate together with the increasing requirements on solvency have put significant strain on pension funds and insurance companies, whose liabilities consist of a fixed investment return or promises of payment, as in the case of defined benefit plans. The precise magnitude and adverse effects of low interest rates, see Antolin et al. [2] and Kablau and Wedow [12], are more likely to arise for life insurance companies (as compared to non-life) and the effects would also depend on the level and type of guarantees offered by these institutions.

For life insurance companies, where the duration of liabilities exceeds those of assets, a period of protracted low interest rates poses challenges for asset-liability management in that current lower returns are expected to meet the past return assumptions, see [1, 4]. On the other hand, embedded options such as guaranteed benefits in unit-linked contracts and/or options for renewing contracts at guaranteed interest rates place a large burden for the pension providers as time passes and interest rates stay low.

Insurers and pension funds can address the risk of persistently low interest rates in different ways, [2]. First, insurers can seek to increase the duration of their assets to ensure a better duration match between assets and liabilities. Second, liabilities can be progressively reduced by lowering guaranteed rates of new contracts. Also, some parametric adjustments to existing contracts can be renegotiated such as an increase of contribution rate or some discretion in the level of revaluation of pension benefits.

In occupational pension plans, the common trend resulting from falling interest rates and stock returns and the increase in capital requirement is a shift from a defined benefit to a defined contribution and the abandonment of the financial guarantees. Whether it is a defined-benefit or a defined contribution (DC) plan or a mix of both, the investment performance and funding ratios are likely to suffer under a low interest rate environment. For a DB plan the impact of protracted low interest is the largest when the future benefits are fixed (i.e., guaranteed return not linked to economic variables such as salaries or inflation). For DC plans, the size of the effect depends on the fund's investment strategy with lower investment returns that translate into lower benefits. If the DC plan contains some guarantees to contributors low interest rates increase the cost of providing the guarantee for the sponsor.

At the same time, most of these DC schemes have followed a collective approach in their second pillar and sometimes even in their third pillar (private 
pension plans). In Denmark [15], the statutory savings based supplementary pension (ATP) is a compulsory DC occupational scheme collective insurance based. Under the ATP, $20 \%$ of the contribution serves as an investment buffer for indexations and unexpected longevity increases. Collective pension schemes are also the dominant form of saving for retirement in the Netherlands, see [11, 17, 20].

Under a collective defined contribution scheme (CDC) members own a proportionate share of the aggregated collective investment rather than an individual share of the underlying assets as for the case of the individual DC (IDC). Under CDC the contribution rate is fixed and both pensioners and workers share the ups and downs of investment returns while the implementation costs are low. Therefore, pensions can be reduced and/or contributions increased. In the accumulation phase CDC would outperform IDC with the latter mainly investing in bonds for elderly workers. However, there is some risk of the pension provider transferring a fair share of losses away from pensioners to contributors, so strong regulatory rules need to be in place. Also, both CDC and IDC do not guarantee any particular income in retirement since equity returns are volatile.

For insurers offering pension plans in the third pillar, 2015 has marked a change in product strategy. Some companies plan to exit the traditional life insurance market by no longer selling classical guarantee products. In the UK, the Pension Scheme Act 2015 sets up a new legislate framework for private pensions and is intended to encourage and enable shared risk pension schemes and collective benefits.

There is an obvious trade-off between the life insurers and members' preferences. While the former wants to avoid unhedged guarantees, especially under a low interest environment and with Solvency II in place, the member wants a satisfactory level of pension benefits. With this in mind, we aim to present a pension design to bridge the gaps between insurer and policyholder that offers an adequate level of benefits to the member while does not endanger the long-term sustainability of the plan. With the aim of mitigating the financial risks of both the individual fund and level of benefits, our pension design considers a combination of features of different products with a collective approach, such as unit-linked products and annuity pools, together with some optimisation elements to get a high value of initial pension and stable pension payment over time.

The next section describes the design of our proposed pension product with no guarantees and discusses its main challenges in both the accumulation and retirement phase. Section 3 concludes and makes suggestions for further research.

\section{An alternative pension product design ("maximal with-profit")}

In this section, we introduce a pension design that avoids the two core guarantees inherent in the classical pension products: guaranteed rate of interest and guaranteed mortality rates. Our proposed design, we call it "maximal with-profit", offers a new understanding of security through smoothing corridors in both accumulation and retirement phases and additional safety layers in case of adverse financial conditions.

We use a similar idea to the one suggested in [5], where the so-called annuity pools are discussed. Annuity pools guarantee the insured solely a lifelong pension 


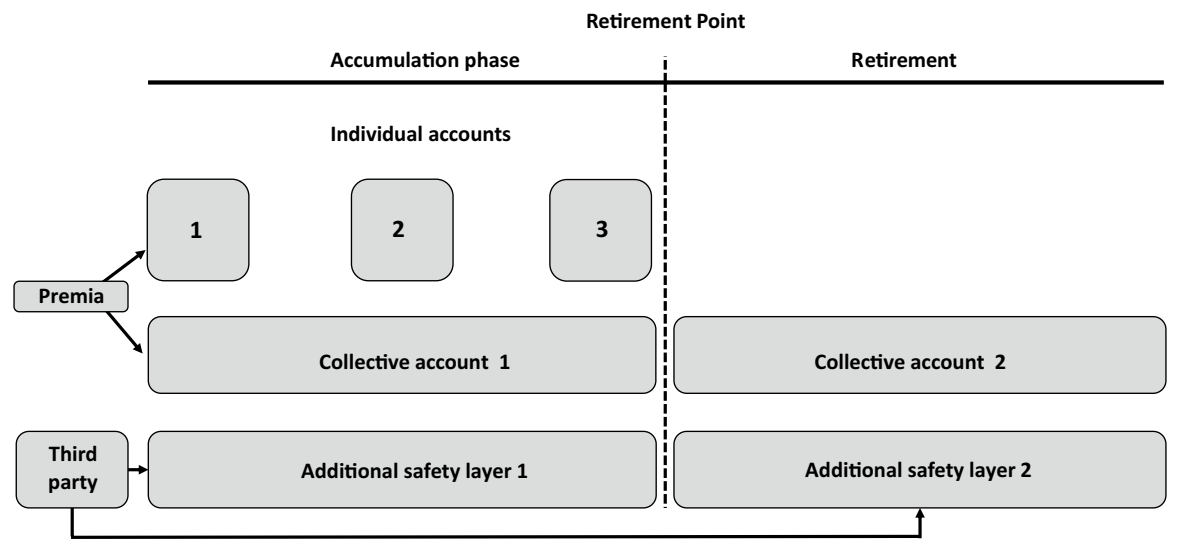

Fig. 1 A possible product design for the accumulation and retirement phases containing individual and collective accounts along with the additional safety layers. Own source

that is feasible for the collective of pensioners under the actual interest and actually expected development of the mortality rates. In equidistant intervals, for instance yearly, the pension amount can be adjusted if necessary (both upward and downward modifications are possible). Further, annuity pools are using the idea of a tontine: a redistribution of assets from those who die before average to those who live longer. The advantages for the insurer are obvious: a better solvency position or reduced liabilities. The feedback strategy and the absence of the safety margins lead to a higher initial pension which represents the biggest advantage of such a construction from the pensioner's standpoint. However, if life expectancy of the customers increases on average more than calculated, pensions will decrease.

Our proposed design goes beyond the annuity pools and unit-linked (unitised with-profit) schemes. The idea is to replace traditional guarantees with low volatility, mainly achieved by collective smoothing algorithms and an adequate asset management. Waiving traditional guarantees allows a more return-oriented asset management and as a consequence higher expected returns for the policyholder and reduced liabilities for the employer. In order to avoid any ambiguities, we would like to emphasise that the choice of funds and asset management lies completely in the hands of insurance companies.

First of all, we divide our considerations on the time scale into two parts, as illustrated in Fig. 1. The first time interval lasts from the inception of a contract to the retirement point - the accumulation phase, the second interval, is the retirement phase which ends upon death of the insured person. ${ }^{1}$

At the retirement point, depending on regulations in place, the product design might stipulate the payment of the accumulated amount as a lump sum, i.e. the

\footnotetext{
1 The second interval lasts beyond death in the case of survivor benefits or can start earlier if disability benefits are granted in the contract.
} 
contract ends at the retirement point. However, in many countries a transition to the retirement phase is obligatory.

The overall target of the maximal with-profit is twofold: to maximise the total saved amount (alternatively the first pension or the discounted pension payments expected at the retirement point) and to keep the pension evolution inside a corridor, mitigating the risk of a decrease. With this in mind, our model uses the corridor volatility smoothing method, collective mechanisms and financial safety layers.

At the retirement point, if the considered product allows for the retirement phase, we transfer the saved amount into the new collective fund and calculate the first premium accordingly. It is clear, the higher the savings for a concrete individual are the higher will be her/his first (initial) pension. The smoothing mechanism in the retirement phase again consists of interaction between two layers: the collective fund and an additional safety layer. This allows to increase the pensions if the underlying funds go up and prevents, to some extent, decreasing the pensions if the funds go down. In the extreme case that the actual market situation becomes not manageable for the insurance company and the safety layer is empty, the pensions would need to be reduced. See Example 3 below for a simulation of such a situation.

In the next subsections we explain with more detail a corridor smoothing method that can be applied both in the saving and in the retirement phases, the redistribution index that calculates a fair share of the accumulated collective wealth for the individual, the additional safety layer, the characteristics of the retirement phase and the optimisation targets.

\subsection{Corridor smoothing in the saving phase}

We consider the corridor smoothing procedure from the point of view of an insurance company. Assume for simplicity that the insurance company has chosen two funds, say $F$ and $H$. The fund $F$ is supposed to be more risky and is aimed at having higher returns while $H$ is more conservative and is used mainly to reduce volatility of the fund $F$. However, it is possible to choose $F=H$. Since the smoothing procedure will be applied on two funds through exchange of units, long-term investments and even illiquid product types are allowed. The asset management of the insurance company controls the structure and the evolution of both funds.

We design an individual pension contract as follows. The net premia are divided, under an agreed percentage, into the individual and the collective part. The individual part is invested into the fund $F$, the collective part is invested into $H$. Thus, all insured are paying a part of their premia into the joint collective account (Collective account 1 in Fig. 1), and the remaining part into their individual accounts. For products containing a retirement phase, the amount saved in the individual accounts plus a percentage of the collective fund are transferred to the collective account in the retirement phase (Collective account 2 in Fig. 1) at the retirement age of the insured. Apart from this transfer, the pool of contributions and the pool of pensions are independent in the sense that there is no interaction like for instance in the PAYG scheme. 


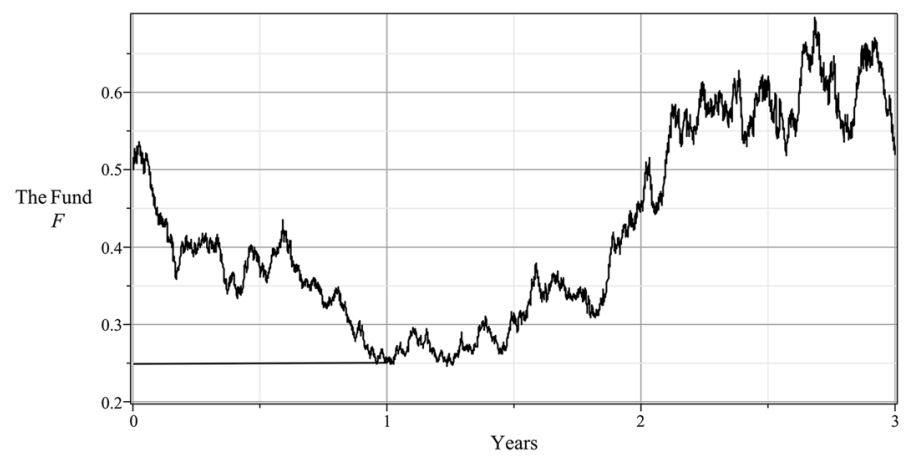

Fig. 2 A possible evolution of the individual fund $F$, where the decrease in value from $F_{0}=0.5$ to $F_{1}=0.25$ amounts $50 \%$. If the chosen $k$ is smaller than 50 then a part $q \%$, stipulated by contract, of the excess of loss $\left((100-k) F_{0}-F_{1}\right)$ will be added to the individual account. Own source

Assume for the moment that there are no premium payments, surrender or deaths in the considered periods. Let $F_{0}$ be the value of an individual fund at time zero. Let further $k$ be a fixed real number from the interval $[0,100]$. The parameter $k$ determines a volatility smoothing corridor in the following sense. The upward and downward movements of the individual fund $F$ are observed at discrete time points. If the current value of the fund compared to the previous observation lies outside the interval $[100 \%-k \%, 100 \%+k \%]$ it has to be adjusted as explained below. If after a certain period of time, say after a year, the fund $F$ performs $k \%$ worse than the year before, a certain part, say $q \%$, of the deficit will be transferred from the collective account into the individual one. If the fund $F$ performs $k \%$ better, a percentage of the excess, say $p \%$ will be transferred into the collective account. An example is given in Fig. 2. The same procedure will be repeated after the next year. However, the reference value will be $F_{1}$. Thus, the collective account helps to keep the evolution of the individual account inside the corridor. For the case that the collective account can become empty an additional safety layer can be introduced to the model. Note that all contracts in one scheme will use the same parameters $q$ and $p$. The parameter $k$ can be the same for all contributors or be chosen individually.

Example 1 Let us fix $k=10, p=25$ and $q=50$ by the start of the contract. A possible evolution of the fund $F$ over 3 years is shown in Fig. 2. In this scenario, we see that if the initial value $F_{0}=0.5$ the value after one year is $F_{1}=0.25$. Since the decrease of $50 \%$ exceeds the given boundary of $10 \%$, the individual fund gets capital from the collective fund in the amount of $q \%=50 \%$ of the loss exceeding the lower corridor boundary: $F_{0} \frac{100-k}{100}-F_{1}$. Thus, the new value of the fund $F$ at time 1 , we denote it by $F_{1}^{\text {new }}$, is

$$
F_{1}^{\text {new }}=F_{1}+\frac{q}{100}\left(\frac{100-k}{100} F_{0}-F_{1}\right)=0.25+0.5(0.9 \cdot 0.5-0.25)=0.35 \text {. }
$$

We start the next period with the initial value $F_{1}^{\text {new }}=0.35$. Then, as shown in Fig. 3, the value of the fund $F$ at time 2 is given by 0.7 . Since the increase is more than 


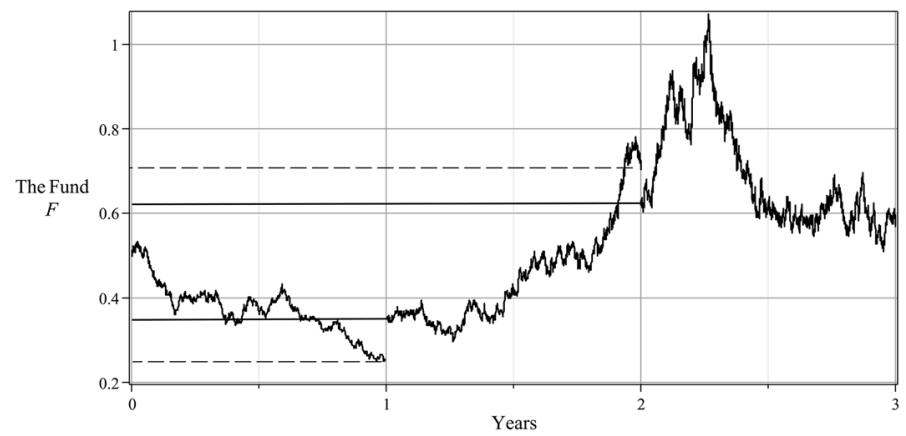

Fig. 3 The evolution of the smoothed fund $F$ with adjusted values after the 1 st and 2 nd year. Own source

$10 \%$, the individual fund transfers $p \%=25 \%$ of the excess to the collective account. The new value of the fund after the application of the smoothing strategy at time 2 is given by

$$
F_{2}^{\text {new }}=0.7-\frac{p}{100}\left(0.7-\frac{100+k}{100} F_{1}^{\text {new }}\right)=0.7-0.25(0.7-1.1 \cdot 0.35)=0.62125 .
$$

And finally, starting with initial value 0.62125 we end up with 0.6 in year 3 . The decrease stays inside the corridor and it is not needed to modify the process.

Please note that the paths in both Figs. 2 and 3 are identical in the time period $[0,1]$ and differ afterwards. This is due to the fact that by changing the initial value also the evolution of the process might change. The high values of the fund $F$ during the period $[2,3]$ are not taken into consideration because the smoothing strategy is assumed to be applied yearly. The frequency of the adjustments can be modified. However, the following aspects have to be taken into account. Shorter time intervals will increase the impact of the volatility and consequently require more frequent adjustments. On the one hand, it will increase the transaction costs. On the other hand, using long-term or illiquid assets would not even allow for very frequent adjustments.

In general, it must be noted that applying the smoothing on the neighbouring observation points might ignore a continuous decrease of the fund without the possibility to react in the framework of the strategy described above. For instance for $k=10$ the fund might develop like shown in Fig. 4: the fund value at any observation point is smaller than in the previous year but the decrease is less than $k \%=10 \%$, i.e. no actions are allowed. A solution could be to always compare the values of the fund with the initial value at time zero. In this case, given the situation in Fig. 4, already after the 2nd year (decrease of $23 \%$ compared to the initial value of 0.5 ) the considered individual fund gets financial help from the collective fund. Another possibility to improve the situation would be to apply a feedback strategy for $k$. 


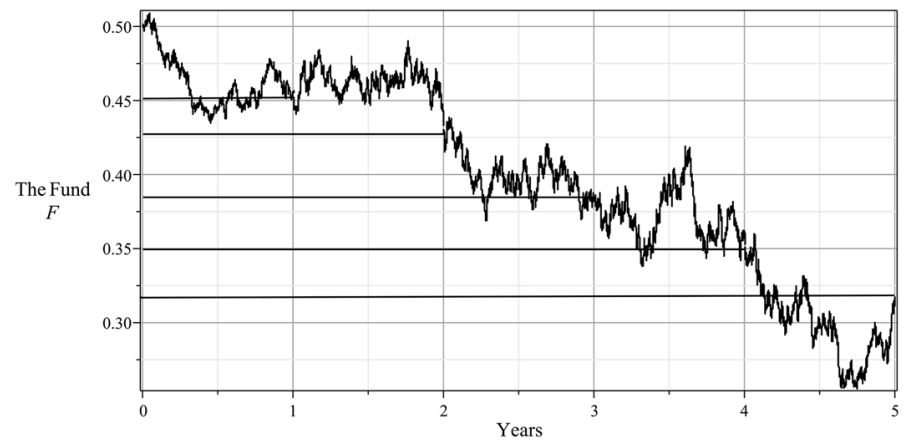

Fig. 4 The situation of a continuous decrease inside the corridor of $k \%$. Own source

\subsection{Individual smoothing: better or not?}

From an individual point of view, it is more desirable that following the development of the fund, a feedback strategy governing/changing the value of $k$, say yearly, would be preferred. This might yield more chances for the individual to maximise the saved amount and consequently the value of pensions than a constant $k$ chosen at the beginning of the contract. The running management expenses will not increase considerably. Thus, one can maximise the whole saved amount at the time of retirement (given the insured person stays alive and will not surrender) over all $k \in[0,100]$ to be chosen at the adjustment times post-smoothing. Due to different premium payment behaviour and different run-time of the contracts, it would make sense to determine the boundary $k$ individually for each contract. However, depending on the stipulated help procedure from the collective account and/or from the third layer, the individual accounts might become dependent, i.e. the optimal choice of the level $k$ will depend on the choices made for other individuals in the pool of insured. Multivariate optimisation problems with dependent variables are not easy tasks to handle. For the sake of transparency, insurance companies and regulating authorities might want to simplify the calculation procedures and require the same level $k$ for all individual contracts. This method can be justified from the mathematical point of view by applying the mean-field game theory. If the pool of insured is large enough and every contractor has the same risk-averseness, it can be shown that the best choice of $k$ for each contract depends just on the total amount saved in all individual accounts and the collective amount, i.e. the same $k$ is used for everyone.

\subsection{Products with retirement phase}

For products with a retirement phase, one can think about the first pension as a target to optimise. By signing of the contract, an insurance company can agree to update the insured not only on the development of the fund but also on the first expected pension under the current market situation and mortality rates. In this case one would need an (exogenously given, see Sect. 2.6) condition specifying the first 
pension in dependence of the savings of a concrete individual. Such a condition might be a parameter gained from the pool of pensioners which is up to the transfer of savings at the transition point independent of the pool of active contributors as one can see in Fig. 1.

\subsection{Redistribution index}

It is important to give a cohort that leaves the saving phase a fair share of the accumulated collective wealth, Collective account 1 in Fig. 1. A simple solution to obtain an indicator would be to consider the relation of the total premia paid by the individual to the total premia paid by all individuals in the accumulation phase. Applying this reference number to the current collective fund value would yield the desired amount.

However, this solution does not take into account the possibility of late lump sum premium payments close to the retirement point. Imagine the following situation. Person 1 and Person 2 are paying premia yearly to the amount of $P_{1}$ and $P_{2}$ correspondingly with $P_{1}<P_{2}$. After 30 years and one year before the retirement, Person 1 decides to pay $30\left(P_{2}-P_{1}\right)$ as a lump sum premium. It means the total premium amount of the Persons 1 and 2 are equal and so is their share on the collective capital. If the collective fund has been increasing in the recent years, Person 1 is making an arbitrage by participating in gains to the same percentage as Person 2. Also, this situation contradicts the core idea of our product design: partially collective risk sharing. The risk is totally with Person 2, but the gains are equally distributed between Persons 1 and 2 .

A possible solution would be to put weights on account values in different time intervals: the earlier a value the higher the weight. An example is provided by the calculation procedures in redistribution of hidden reserves (the difference between market and book value of assets) in Germany. There, the late payments are penalised so that a situation described above is not possible. For further examples of redistribution procedures see for instance $[3,8,13]$ and references therein.

Another possibility to define a redistribution index is to use the total amount of shares purchased for an individual from her/his contributions into the collective account divided by the total number of shares in the collective account. In the worst case scenario, when the asset prices fall sharply this could be leveraged by policyholders through a large contribution initiating an acquisition of a substantial amount of shares at cheap prices. However, one expects that the asset prices increase in expectation because otherwise entering or staying in the scheme would not be beneficial to the individuals. Thus, usually those who pay in later face the risk of having a lesser amount of shares at the end of the contribution phase compared to those who have been paying in regularly.

Since the redistribution index plays a crucial role in the determination of the first pension, it needs a detailed discussion concerning the desired properties and possible outcomes. However, such a discussion goes beyond the scope of the present paper. 


\subsection{Additional safety layer}

In the case that the market goes down and the collective account becomes empty an additional safety layer can be introduced in both the accumulation and the retirement phases, see Fig. 1. This layer should be financed by a third party, for instance the employer in the case of occupational pension insurance. The investment form should be secure like government bonds or bank account.

The financial support procedure from the third layer has to be stipulated by contract and will depend on the specific product design, negotiations and requirements of the regulating authorities. If the proposed product is used as an occupational pension scheme, the employer might overtake the role of the third party by paying a certain amount of money, say monthly, into the third layer. Once the third layer is empty, no additional help will be provided.

However, in the extreme case that the third party agrees to overtake any unexpected losses, the product indeed will involve guarantees.

A particular risk accompanies the first years after the introduction of a new product. In case the market goes down, the additional safety layer will not contain a huge amount of money and might not be able to buffer the losses of the collective fund. If the additional layer becomes empty, a possible solution might be to distribute the available money from the collective account between the individual accounts according to a redistribution index specified contractually.

\subsection{The retirement phase}

In the retirement phase, we have a pure collective model (Collective account 2) and possibly an additional safety layer, as shown in Fig. 1. During the transition to the retirement phase the amount of the first pension has to be calculated due to indicators depending on the saved amount (individual account and part of the Collective account 1 according to the redistribution index) and some characteristics of the collective account in the retirement phase, for instance the degree of capital cover.

The target is to ensure the highest possible amount of initial pension and with low changes in the revaluation of pension payments. We follow a similar procedure like in the accumulation phase. However, the reference value is not the value of the collective account, but the degree of capital cover (DCC) - the ratio of the value of the collective fund and the present value of future pension payments for all current retirees.

The collective fund but also the value of the future pensions will develop over time, implying the development of the degree of capital cover. The first pensions of the new retirees should be calculated in such a way that the DCC does not change due to the new pensions to be paid and new capital transferred to the collective account in the retirement phase. The so-called "Betriebsrentenstärkungsgesetz" in Germany (the law came into force January 1st, 2018) requires the DCC to be inside the interval $[100 \%, 125 \%]$. Thus, here a smoothing corridor is naturally defined. If the DCC drops below $100 \%$ the safety layer buffers the losses, as far as it is enough 


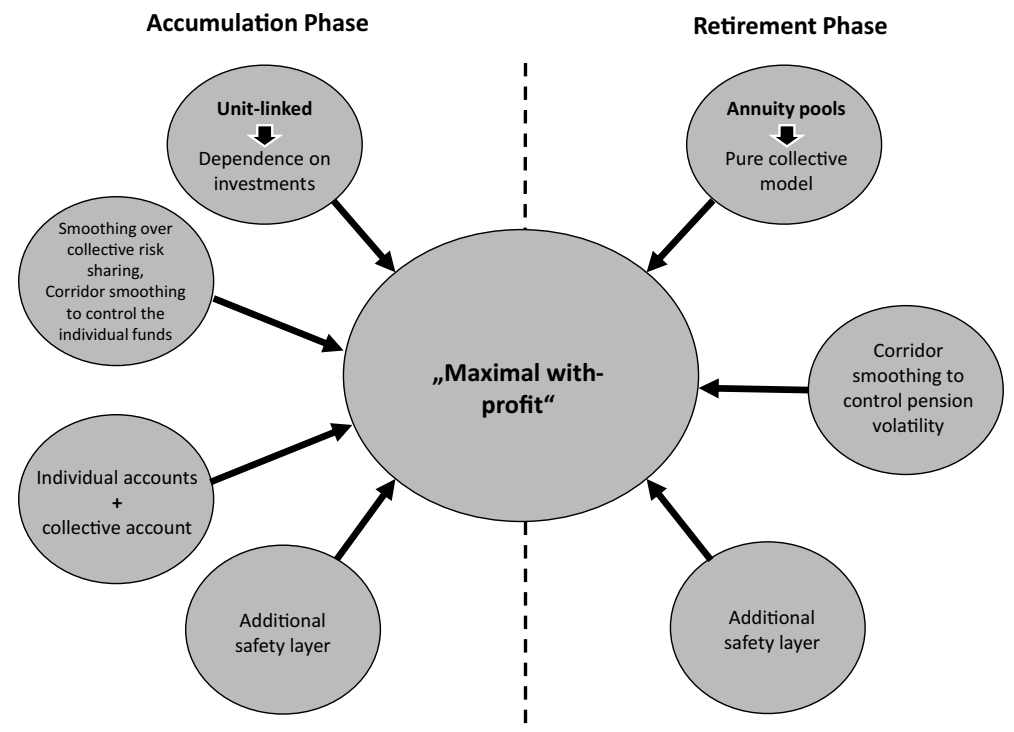

Fig. 5 The structure of "Maximal with-profit" pensions schemes. Own source

money, in such a way that the new DCC again amounts, for instance, to $110 \%$. If the additional safety layer is empty, the pensions should be cut to the level yielding the DCC of at least $100 \%$. Taking for instance $110 \%$ will make sure that DCC will not drop under $100 \%$ immediately after the adjustment, i.e. it acts as an additional buffer.

If the DCC exceeds $125 \%$, the pensions should be increased in such a way that the new DCC is not lower than $110 \%$. However, the insurance company has the freedom to choose the percentage of increase. Acting to the benefit of the insured, the insurance company can maximise the expected future pensions over all possible DCC values (from the interval $[110 \%, 125 \%$ ) determining the pension amount after the upward adjustment. The dilemma here is to decide whether it is better to increase the pensions as much as possible (set DCC to 110\%) or to create an even bigger buffer (set the DCC to $U \% \in(110 \%, 125 \%))$ preventing from possible future pension reductions due to a suboptimal market development.

\section{Conclusion}

The "Betriebsrentenstärkungsgesetz"- the pension reform law-has been adopted for company pension schemes in Germany. This law makes it possible to set up occupational pension plans without guarantees as a part of collective bargaining agreements. Therefore, many insurance companies are currently assessing their occupational pension offerings, which will lead to a run on different products in the coming future. "Maximal with-profit" described in this paper might offer an alternative. In Figure 5 we sum up the most important features of the pension design needed not only for the insurance companies - in terms of solvency_but also for 
the insured-in terms of satisfactory pensions. Every single building block is not new and has been extensively discussed in the literature. The dependence on the investments comes for instance from the unit-linked (in particular from the unitised with-profit) contracts but without the possibility to choose the investment policy by the clients, a smoothing mechanisms allowing for the possibility of a reserve account are discussed in [7], annuity pools yield the pure collective setup in the retirement phase, see [5].

However, to the best of our knowledge, the combination of all these aspects together with the optimisation elements have been never introduced before. In particular, in the accumulation phase, we suggest to invest both the individual and the collective part into different funds while the smoothing mechanism consists in transferring units between these funds instead of transferring money between a fund and a reserve account like described for instance in $[5,7]$. In this way we omit, to some extent, transaction costs and make higher returns possible. A redistribution index helps to determine a fair share of an insured on the collective wealth.

Another important difference to the already existing methods is the maximisation of the total saved amount (the first pension or the total amount of pensions to be paid) over the corridor width for gains and losses. Due to the redistribution index for collective savings, the optimal corridor width will be different for different contracts. Here, the idea of collective sharing comes into its own. Due to different corridor widths and different individual funds, not all contracts will need help simultaneously. Indeed, some of the individual funds will over-perform and finance in that way the losses of the others. For the case of a severe financial crisis, an additional safety layer comes to the aid of the collective fund.

In the retirement phase, we have a pure collective model with the possibility of an additional safety layer. The target is to maximise the future pension payments by simultaneously controlling the volatility. An additional safety layer buffers possible downward movements.

For the better overview, Table 1 shows the most important products on today's pension market.

The three right columns Guarantees, Returns and Risks characterise the crucial features of every product. We see that traditional products offer heavy guarantees, imply no risks for the insured, severe risks for the insurance company and lowest returns. In contrast, unit-linked products offer the highest expected returns, no guarantees and high risk of losing the investments. Dynamic hybrid products by offering guarantees (usually $70 \%, 80 \%$ or $90 \%$ of the sum of premia paid) suffer under the ultra-low interest rate environment in a similar way like traditional designs.

The potential drawbacks to the maximal with-profit are to set up or regulate the value of some of the key variables involved in the proposed pension design. In particular, in the accumulation phase, the main challenges for the development of the product are to determine the splitting strategy of the premia into two funds, establish the value parameter $k$ that determines the volatility smoothing corridor or the percentage of the deficit (excess) to be transferred from the collective (individual) account to the individual (collective) account. Negotiation and bargaining between the insurance company and participants' representative would need to take place to set up new regulatory rules together with the values of these parameters. The size of 


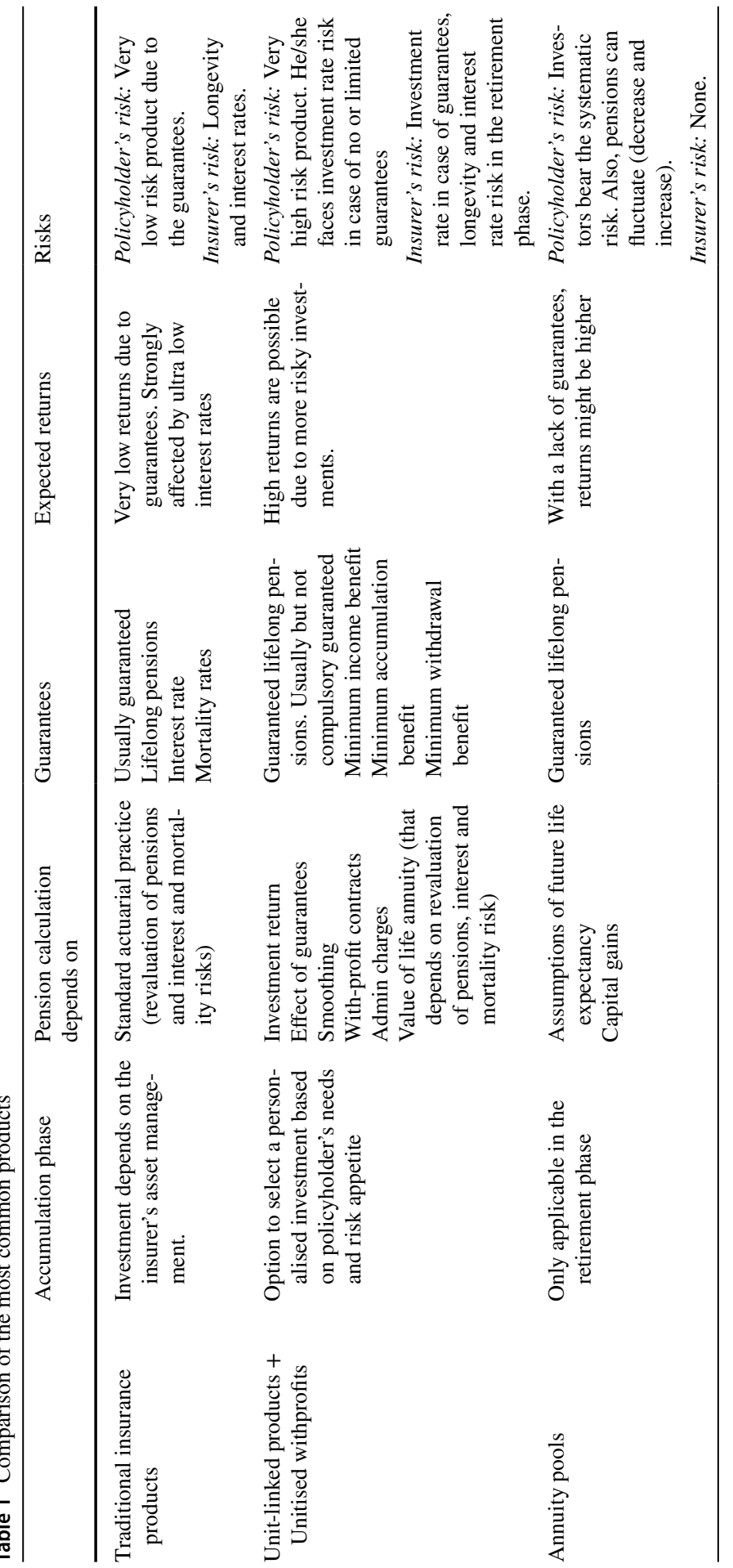




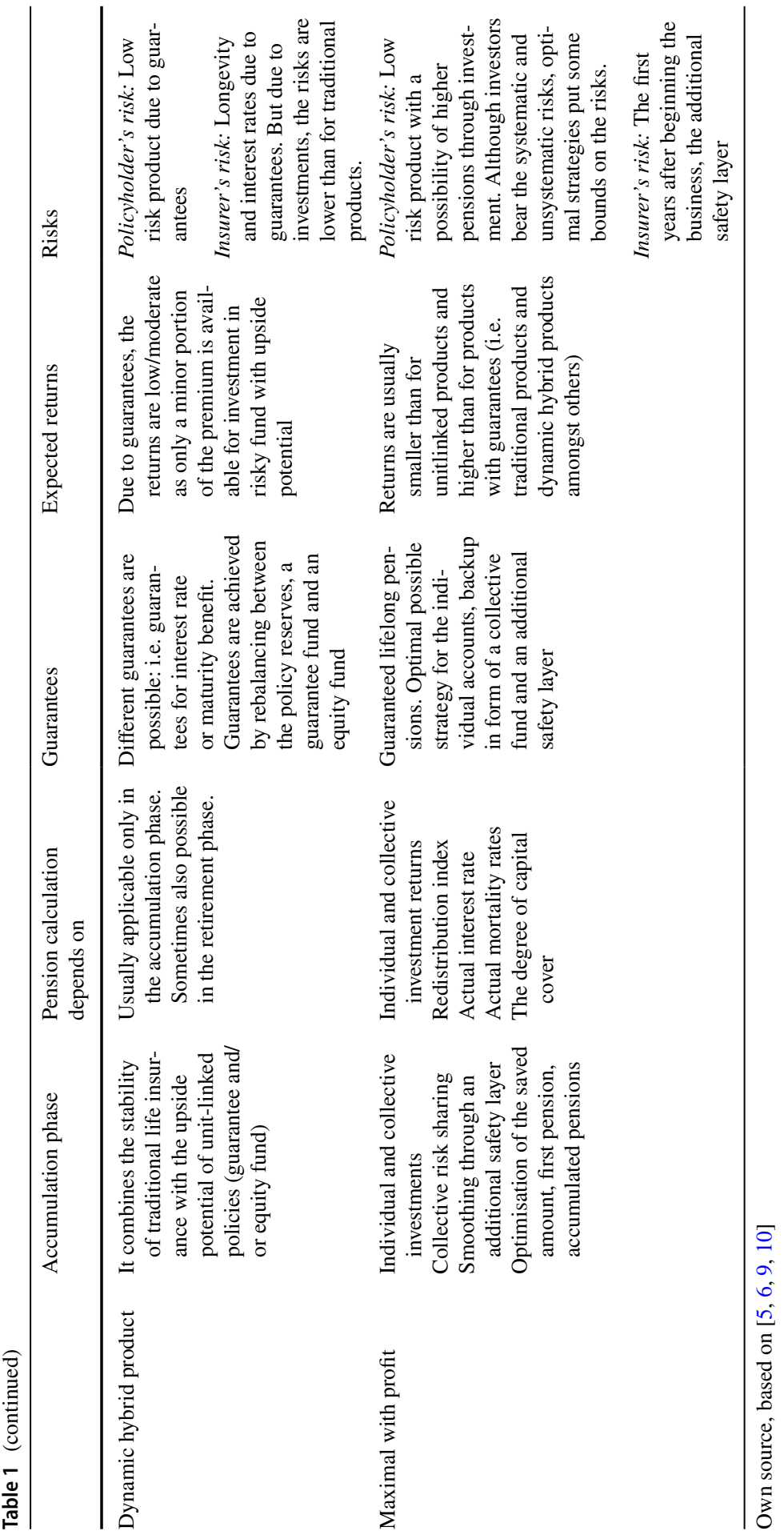


the safety layer could be calculated in different ways. It can be formulated, for example, as the amount that is needed to avoid a complete ruin in $99 \%$ of the cases. As mentioned in Sect. 2.4, the redistribution index plays an essential role when calculating the amount of the initial pension. Consequently, the method to calculate a fair share of the accumulated collective fund considering the rest of the key variables is an important challenge for the maximal with-profit. In the pay-out phase, the bounds of the smoothing corridor should be defined so that the pensioners have a constant amount of the pension payment, i.e. minor changes in the pension revaluation.

Mathematically, all these parameters could also be determined following optimisation procedures. Some constraints can also be included in the optimisation problem so that, for example, the total accumulated capital at retirement is not lower than a threshold with a high probability.

Another important challenge, that goes beyond the scope of the present paper, would be the asset-liability management of both individual and collective funds carried out by the insurance company.

In order to illustrate the advantages of maximal with-profit, we ran Monte-Carlo simulations comparing the new product to a unit-linked contract and a government bond during the accumulation phase and describing possible evolution of pensions in the retirement phase. The results are given in the appendix below.

\section{Appendix: Numerical Examples}

Example 2 (The accumulation phase) For the accumulation phase, we assumed that the underlying funds are following geometric Brownian motions $e^{\mu t+\sigma W_{t}}$ for the individual fund and $e^{\mu t+\sigma B_{t}}$ for the collective fund, where $W$ and $B$ were independent Brownian motions with $\mu=0.045$ and $\sigma=0.06$. In this example, we omit the optimisation procedures and assume $k=0$ through the whole consideration period.

For the government bond we assumed the interest rate of $r=0.0027$ corresponding to the interest rate for a 30-year bond yield in Germany as of the 12th of September 2019 .

The simulations were done for a cohort starting to pay annually contributions of 50 units into individual accounts and 50 units into the collective account at the age of 35 until the retirement age fixed at 65 . As a time step we chose the period of one year and assumed that the premia had been paid yearly.

The underlying investment for the unit-linked product was given by the individual fund described above.

In Fig. 6, one sees the densities of the accumulated capital at the retirement age for the unit-linked (dashed line), the maximal with-profit (solid line) and the government bond (dotted line) gained through 100,000 Monte-Carlo simulations. We see that the density corresponding to the maximal with-profit concentrates the weight between 5000 and 8000 , whereas the values smaller than 5000 do not appear. The unit-linked product features more weight "on the sides", manifesting a higher volatility: excursions in both directions are possible and excursions to the smaller values are more probable despite exactly the same mean as in the maximal with-profit. Thus, smoothing volatility considerably reduces the probability to accumulate a 


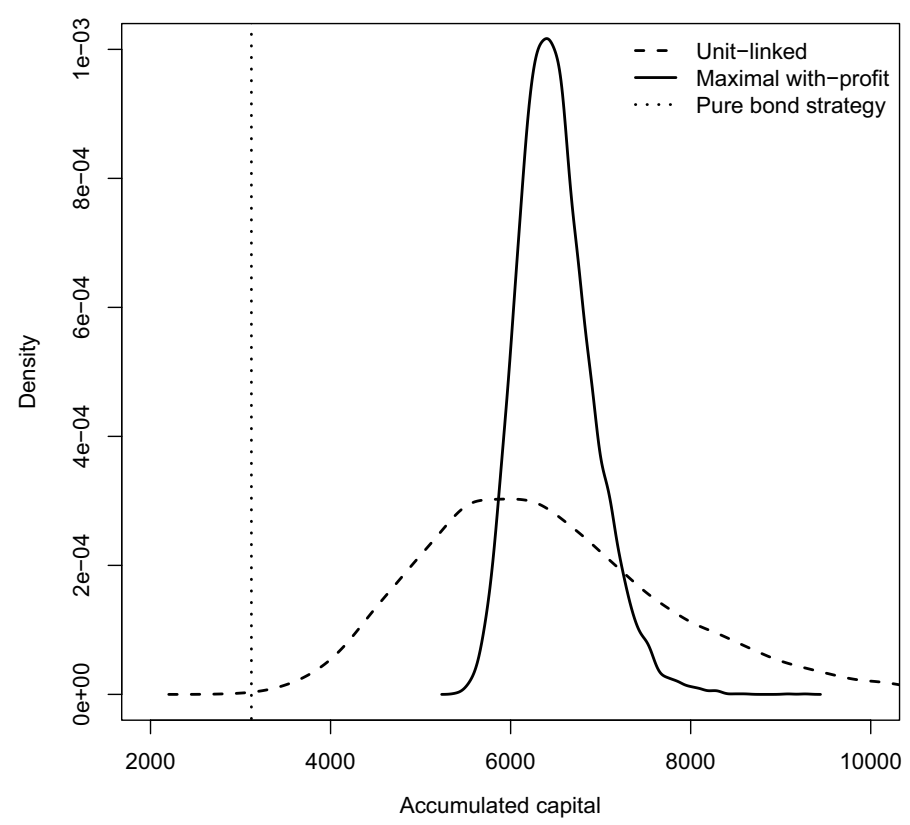

Fig. 6 The densities of the accumulated capital for unit-linked, maximal with-profit and government bond

capital bigger than 8000 but makes "an adequate capital" more secure even for a non-optimal level $k=0$. The government bond might yield a better result than the unit-linked contract but is definitely inferior to the maximal with-profit.

Example 3 (The retirement phase) In this example, we simulated the development of the degree of capital cover (DCC), the resulting pensions over time and their adjustments due to exiting of the DCC from the interval [100\%, 125\%]. For the mortality, we assume the Gompertz law, i.e. the rate of mortality grows exponentially with age. If the DCC exceeds $125 \%$ we adjust the pensions so that the new DCC amounts to $110 \%$.

In Fig. 7, we see the development of the DCC (solid line) and the adjusted pensions (dotted/dashed line). Assuming $e^{0.015 t+0.01 W_{t}}$, where $W$ is a Brownian motion, for the fund, yields just upward adjustments of the pensions due to the natural buffer coming from the reduction of the DCC to $110 \%$ and not $100 \%$. 


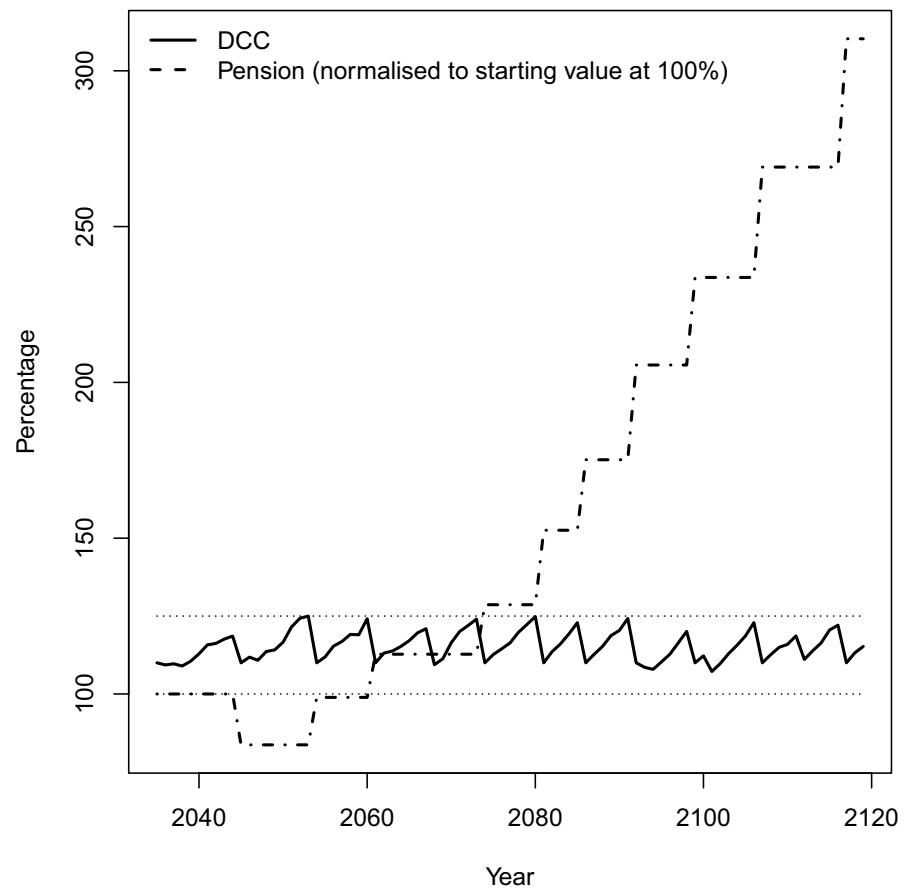

Fig. 7 The evolution of DCC and pension adjustments

In Fig. 8, we used different parameters, $\mu=0.01$ and $\sigma=0.01$, for the fund and implemented random shocks approximately every 10 years. For that purpose we generated an iid. sequence of random variables with values in $\{0,1\}$ and $10 \%$ probability for 1 . In case of outcome 1 , an additional downward jump, $\chi_{1}^{2}$ distributed, was added to the value of the process $W$, which was a standard Brownian motion otherwise. As a result, the pensions had to be reduced twice. We did not implement the third layer in this example as we wanted to keep things simple.

In maximal with-profit, the feedback strategy along with the corridor smoothing method and collective risk sharing combines the advantages of the unit-linked and traditional products. The possibility of strategy adjustment during the contract's runtime compromises the interests of the insurance company and the insured.

In our future research we will address the mathematical aspects of the proposed pension model design and present some techniques allowing to determine the optimal feedback strategies for the optimisation problems mentioned above. 


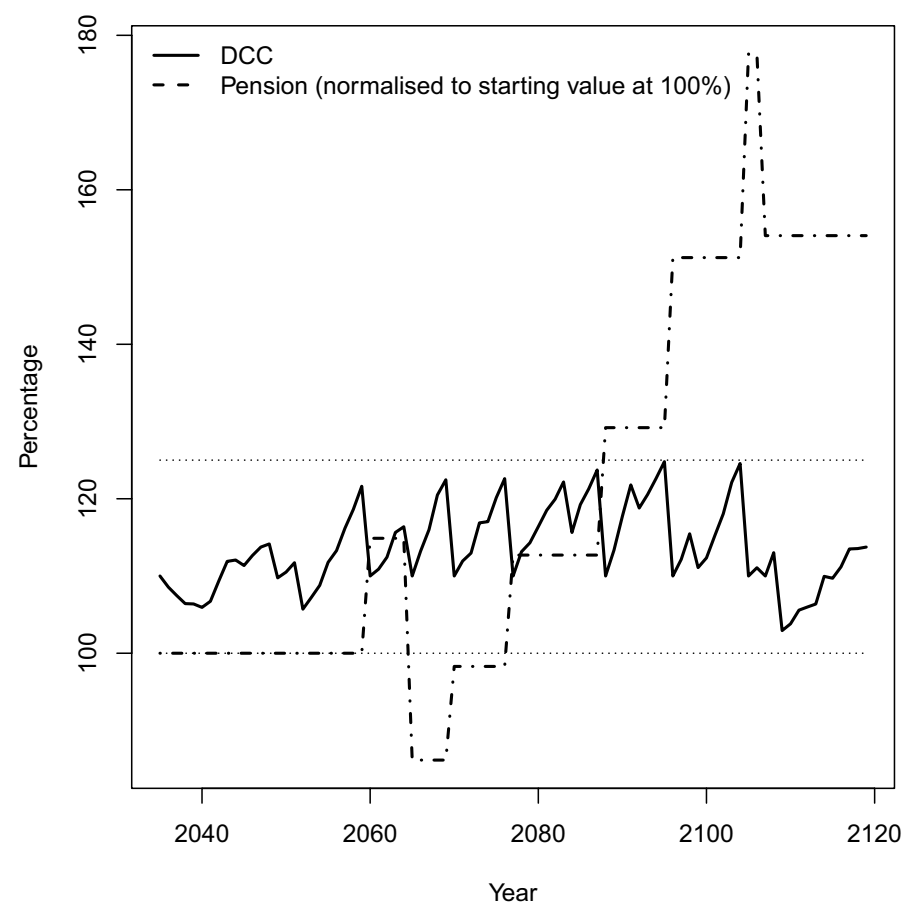

Fig. 8 The evolution of DCC and pension adjustments under a market shock

Acknowledgements Open access funding provided by Austrian Science Fund (FWF). The authors are grateful to the unknown reviewers for their careful and meticulous reading of the paper and valuable comments. The first author is grateful for the financial assistance received from the Spanish Ministry of the Economy and Competitiveness [project ECO2015-65826-P]. The research of the second author was funded by the Austrian Science Fund (FWF), Project number V 603-N35. All authors would like to thank Cordelia Rudolph, msg life, without whom this paper would not have been possible.

Open Access This article is licensed under a Creative Commons Attribution 4.0 International License, which permits use, sharing, adaptation, distribution and reproduction in any medium or format, as long as you give appropriate credit to the original author(s) and the source, provide a link to the Creative Commons licence, and indicate if changes were made. The images or other third party material in this article are included in the article's Creative Commons licence, unless indicated otherwise in a credit line to the material. If material is not included in the article's Creative Commons licence and your intended use is not permitted by statutory regulation or exceeds the permitted use, you will need to obtain permission directly from the copyright holder. To view a copy of this licence, visit http://creativecommons.org/licen ses/by/4.0/.

\section{References}

1. Albrecher H, Embrechts P, Filipovic D, Harrison GW, Koch-Medina P, Loisel S, Vanini P, Wagner J (2016) Old-age provision: past, present, future. Eur Actuar J 6(2):287-306

2. Antolin P, Schich S, Yermo J (2011) The economic impact of protracted low interest rates on pension funds and insurance companies. OECD J Financ Market Trends 1:1-20 
3. Bauer D, Kiesel R, Kling A, Ruß J (2006) Risk-neutral valuation of participating life insurance contracts. Insur Math Econ 39(2):171-183

4. Berdin E, Gründl H (2015) The effects of a low interest rate environment on life insurers. Geneva Papers Risk Insur Issues Pract 40(3):385-415

5. Blome S, Kling A, Ruß J (2018) Annuity Pools-Wackelrente oder sinnvolle Produktinnovation? Zeitschrift für Versicherungswesen 11

6. Bohnert A (2013) The market of dynamic hybrid products in Germany: concept, risk-return profiles, and market overview. Zeitschrift für die gesamte Versicherungswissenschaft 102(5):555-575

7. Goecke O (2013) Pension saving schemes with return smoothing mechanism. Insur Math Econ 53(3):678-689

8. Graf S, Kling A, Ruß J (2011) Risk analysis and valuation of life insurance contracts: combining actuarial and financial approaches. Insur Math Econ 49(1):115-125

9. Hambardzumyan H, Korn R (2019) Dynamic hybrid products with guarantees - an optimal portfolio framework. Insur Math Econ 84:54-66

10. Hardy M (2003) Investment guarantees: modeling and risk management for equity-linked life insurance. Wiley, New York

11. Hoevenaars RPMM, Ponds EHM (2008) Valuation of intergenerational transfers in funded collective pension schemes. Insur Math Econ 42:578-593

12. Kablau A, Wedow M (2011) Gauging the impact of a low-interest rate environment on German life insurers, Deutsche Bundesbank discussion paper series 2: banking and financial studies 2

13. Kling A, Richter A, Ruß J (2007) The interaction of guarantees, surplus distribution, and asset allocation in with-profit life insurance policies. Insur Math Econ 40(1):164-178

14. Milevsky MA, Thomas SS (2016) Equitable retirement income tontines: mixing cohorts without discriminating. ASTIN Bull 46(3):571-604

15. OECD, Pensions at a Glance (2017) OECD and G20 indicators. OECD Publishing, Paris. https:// doi.org/10.1787/pension_glance-2017-en

16. Ponds EHM, Van Riel B (2007) The recent evolution of pension funds in the Netherlands: the trend to hybrid DB-DC plans and beyond, working paper available at SSRN

17. Ponds EHM, Van Riel B (2009) Sharing risk: the Netherlands' new approach to pensions. J Pension Econ Finance 8(1):91-105

18. Piggott J, Valdez EA, Detzel BB (2005) The simple analytics of a pooled annuity fund. J Risk Insur $72(3): 497-520$

19. Stamos MZ (2008) Optimal consumption and portfolio choice for pooled annuity funds. Insur Math Econ 43(1):56-68

20. Van Binsbergen JH, Broeders D, De Jong M, Koijen RSJ (2014) Collective pension schemes and individual choice. J Pension Econ Finance 13(2):210-225

Publisher's Note Springer Nature remains neutral with regard to jurisdictional claims in published maps and institutional affiliations. 